\title{
BMJ Open Treating gambling disorder with as needed administration of intranasal naloxone: a pilot study to evaluate acceptability, feasibility and outcomes
}

\author{
Sari Castrén, ${ }^{\oplus, 2}$ Niklas Mäkelä,, ${ }^{3,4}$ Janne Haikola, ${ }^{5}$ Anne H Salonen,, \\ Roger Crystal, ${ }^{7}$ Mika Scheinin, ${ }^{8}$ Hannu Alho ${ }^{3,9}$
}

To cite: Castrén S, Mäkelä N, Haikola J, et al. Treating gambling disorder with as needed administration of intranasal naloxone: a pilot study to evaluate acceptability, feasibility and outcomes. BMJ Open 2019;9:e023728. doi:10.1136/ bmjopen-2018-023728

- Prepublication history and additional material for this paper are available online. To view these files, please visit the journal online (http://dx.doi org/10.1136/bmjopen-2018023728).

Received 24 April 2018 Revised 8 April 2019 Accepted 21 June 2019

Check for updates

(C) Author(s) (or their employer(s)) 2019. Re-use permitted under CC BY-NC. No commercial re-use. See rights and permissions. Published by BMJ.

For numbered affiliations see end of article.

Correspondence to

Dr Sari Castrén;

sari.castren@thl.fi

\section{ABSTRACT}

Background and aim There is growing interest in the use of medication-assisted treatments for gambling disorder (GD). Opioid receptor antagonists are hypothesised to blunt the craving associated with gambling. This study was designed to assess the feasibility of using an intranasal naloxone spray to treat GD.

Design An 8-week, open-label, uncontrolled pilot study. Setting A single study site in the capital region of Finland. Subjects Twenty problem gamblers (nine men) were randomised into two groups. Group $A(n=10)$ took one dose into one nostril (2 $\mathrm{mg}$ naloxone), as needed, with a maximum of 4 doses/day (max. $8 \mathrm{mg} /$ day). Group B $(n=10)$ took one dose into each nostril ( $4 \mathrm{mg}$ naloxone) as needed, with a maximum of 4 doses/day (max. $16 \mathrm{mg} /$ day).

Intervention Naloxone hydrochloride nasal spray. Measures Acceptability and feasibility of the intervention were assessed. Use of study medication, adverse events, gambling frequency and gambling expenditure were recorded in a mobile diary. Problem gambling: South Oaks Gambling Screen (SOGS), depressive symptoms: Beck Depression Inventory (BDI) and alcohol use: Alcohol Use Disorders Identification Test were recorded.

Results Study completion rate was $90 \%$. Acceptability and feasibility scores were high. Group B used intranasal naloxone more frequently than group $A$, and consequently used more naloxone. No serious adverse events were reported. The postintervention SOGS scores were lower (median $=4(\mathrm{IQR}=3.75)$ versus preintervention scores (median=12 (IQR=4.75)). Depressive symptoms were reduced during the trial (preintervention $\mathrm{BDI}$ median $=9$, $I Q R=9$ vs postintervention $B D I$ median $=6, I Q R=6$ ).

Conclusions The acceptability and feasibility of using intranasal naloxone were high, and no serious adverse events were reported. Preliminary results suggest mixed results in terms of gambling behaviour (ie, reduced frequency but not expenditure) and decreased depressive symptoms.

Trial registration number EudraCT2016-001828-56

\section{INTRODUCTION}

Gambling disorder (GD) is a behavioural addiction that shares neurobiological and clinical similarities with substance use
Strengths and limitations of this study

- Key strength of the study is a novel treatment approach, as-needed intranasal naloxone spray to treat gambling disorder.

- Pilot study forms the basis for an randomised controlled trial (RCT).

- Main limitation of this study was lack of a placebo arm.

- The 'modified' South Oaks Gambling Screen version (gambling in last 12 months (screening) or last 2 months (end)) has not been validated for measuring changes in gambling behaviour.

- Another limitation was the small number of participants; only 11 participants were treatment seekers, 9 participants enrolled after reading a newspaper advertisement about the study.

disorders. ${ }^{12}$ Typical clinical presentations of GD include tolerance, withdrawal symptoms and craving. ${ }^{1}$ These presentations cause many types of harm and significant impairment of an individual's psychological, social and professional functioning. ${ }^{3}$ Despite these harms, treatment seeking is relatively rare. ${ }^{4}$ The reasons for infrequent treatment seeking include fear of stigma, lack of efficacious treatments, and limited availability and access to treatments. ${ }^{5}$ Low adherence to therapy is also common. ${ }^{6}$ Therefore, efficacious, easily used and acceptable (patientfriendly) treatments that can be implemented in real-life clinical practice are needed.

The biological, psychological, social and cultural background factors underlying GD are largely similar to those of other addictive conditions. ${ }^{7}$ To date, psychopharmacological interventions have shown only modest benefits in treating GD. The strongest empirical support exists for the use of mu-opioid receptor (MOR) antagonists such as naltrexone and nalmefene, ${ }^{8}$ although the findings are mixed. Thus, in placebo-controlled 
studies, treatment outcomes with these opioid antagonists have been disappointing, with no statistically significant differences found between treatment arms in the severity of gambling, despite some positive medication effects. ${ }^{9}$ Psychotherapeutic and behavioural treatment approaches can also result in significant improvements in GD patients, as shown with even brief interventions such as a 15 min telephone consultation. ${ }^{1011}$

To date, two different MOR antagonist drugs (naltrexone and nalmefene) have been investigated in the treatment of GD. ${ }^{12-16}$ Orally administered naltrexone and nalmefene share possible common drawbacks that may contribute to their modest effects on gambling behaviour. These include low medication adherence and a relatively long duration of action that could impact activities which require endogenous opioidergic tone. There are potential advantages offered by transient MOR antagonism, that is, an 'as-needed' reduction in MOR availability, with the potential for maintaining physiological reward functions when addiction cues are not present. For as needed applications, intranasal administration of a spray formulation of naloxone exhibits rapid entry of the drug into the systemic circulation, combined with a short elimination half-life in plasma $\left(\sim 2\right.$ hours $\left.^{17-19}\right)$ relative to other opioid antagonists. The intranasal formulation used in the present study is identical to the one described in, ${ }^{19}$ yielding pharmacologically relevant plasma levels as rapidly as an intramuscular injection.

The safety and rapid onset of action of intranasal naloxone, leading to its approval to treat opioid overdose, is supported by several previous clinical trials, ${ }^{19} 20$ and a recent PET imaging study has shown that intranasal naloxone produces high MOR occupancy in the central nervous system within minutes. ${ }^{21}$

We hypothesised that the use of 'as needed' (see Methods and materials section) intranasal naloxone combined with brief telephone consultations might lower the threshold for treatment seeking and could be readily implemented in a variety of clinical settings. Prior to launching a placebo-controlled proof-of-concept study to test this hypothesis, we designed and conducted a feasibility study in order to answer the question: 'Can this study be done?'. ${ }^{22}$ Feasibility studies are used to estimate important parameters that are needed to design a proof-of-concept study, especially when testing a new type of intervention. ${ }^{23-25}$ Thus, the goal of this study was to evaluate the acceptability, feasibility and outcomes of conducting an 8-week treatment trial using as needed naloxone combined with telephone contacts in GD patients with respect to subject recruitment, attrition, adherence, adverse events (AEs) and safety procedures.

\section{METHODS AND MATERIALS}

\section{Recruitment/subjects}

Study participants were recruited by newspaper and online advertisements. Online advertisements were sent to organisations that offer treatment or support services to gamblers seeking help, including Helsinki Gambling Clinic, A-Clinic Foundation (offers treatments for addictions), Peluuri (national gambling helpline) and newspaper advertisements were published in the Helsinki region. These advertisements described the trial's aim to provide support and treatment for GD. The sample size was based on previously reported $^{2627}$ feasibility/pilot studies with similar objectives, a sample size of 20 was considered adequate. A total of 30 individuals contacted the research coordinator per phone or email after completing a self-administered online screen (South Oaks Gambling Screen, SOGS, 'modified' to capture behaviours over the last 12 months). ${ }^{28-30}$ Scoring of the SOGS screen was as follows: (1) $0=$ no problem with gambling, 1-4 some problems with gambling, 5 or more=probable pathological gambler (see modified SOGS last 12 months online supplement S1). Of these, 10 persons were excluded and 20 subjects were enrolled in the study. Of the 20 individuals enrolled in the study, 11 were recruited via treatment or treatment seeking services, and 9 found the study information via newspaper advertisements.

\section{Inclusion criteria}

The inclusion criteria were last-year gambling problem at prescreening ( $S O G S \geq 5$ ), age $>18$ years, able to provide written informed consent, criteria met for GD (Diagnostic and Statistical Manual of Mental Disorders, 5th editon $(\mathrm{DSM}-5))^{1}$ as assessed by clinician interview, fluency in the Finnish language and willingness to fill the mobile gambling and AEs diary, and willingness to comply with other procedures and visits.

\section{Exclusion criteria}

The exclusion criteria were $<8$ weeks since any previous treatment with naltrexone, nalmefene or naloxone; current use of opioids or illicit drugs, as assessed by saliva drug screen; any intranasal medication; active HIV or Hepatitis C virus (HCV) infection; hepatic or renal impairment; serious mental illness as assessed by clinical interview (DSM-5), severe depression (Beck's Depression Inventory, BDI score $>24)^{31}$; women of childbearing potential unless using effective contraception; pregnant or breastfeeding women; persons incapable of providing valid informed consent according to Finnish Medical Research Act \# 188/1999 (eg, being a prisoner, mental retardation).

The study was conducted between the 14 February and the 30 May, 2017, at a single study site at the National Institute for Health and Welfare in Helsinki, Finland, in accordance with the Declaration of Helsinki and Good Clinical Practice. All subjects gave written informed consent. The study protocol, the informed consent form and other study-related materials were reviewed and approved by the Finnish Medicines Agency Fimea (number: Klnro 128/2016) and the National Ethics Committee (number: 152/06.00.01/2016).

\section{Procedures}

Intranasal naxolone and drug administration

The study medication was a nasal multispray formulation of naloxone hydrochloride $(20 \mathrm{mg} / \mathrm{mL}$ nasal spray). One 


\section{Enrolment}

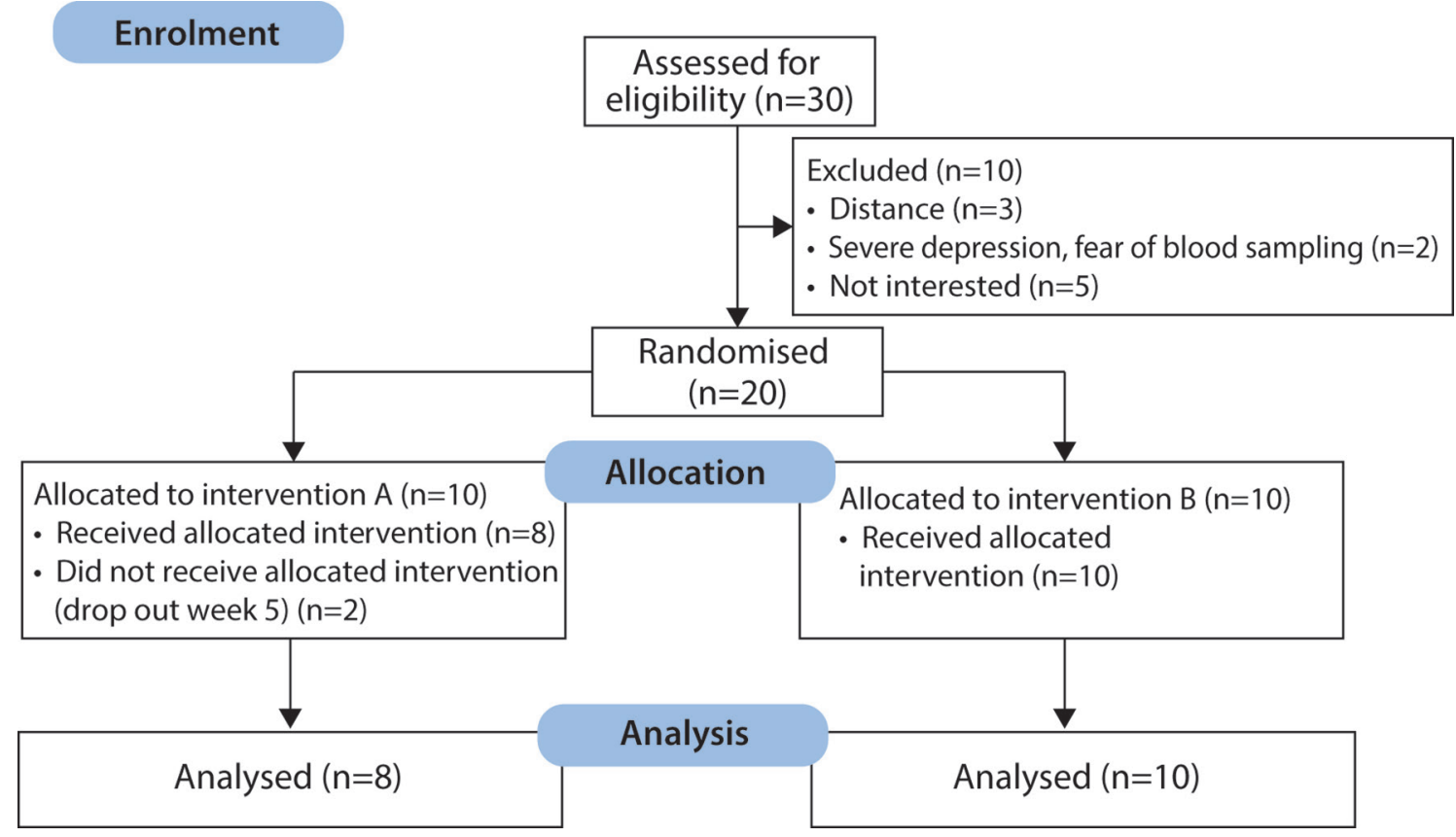

Figure 1 Participant flow (CONSORT diagram). CONSORT, Consolidated Standards of Reporting Trials.

dose delivers $0.1 \mathrm{~mL}$ of the formulation $(2 \mathrm{mg})$ into one nostril. The manufacturer was Sharp Clinical Service (UK) Limited, Crickhowell, UK. The investigational medicinal product was donated by Opiant Pharmaceuticals, Santa Monica, CA, USA, without terms or conditions. The subjects were instructed to administer the study medication in an as-needed manner when experiencing an urge to gamble or in a situation where the individual felt that relapse was imminent.

The subjects $(\mathrm{n}=20)$ were allocated (in an alternating sequence) by the study physician 1:1 into two groups: subjects in group A were instructed to take one dose into one nostril (2mg naloxone), up to four times per day (max. $8 \mathrm{mg}$ /day) with at least 2 hours between each dose. Subjects in group B were instructed to take one dose into both nostrils (4mg naloxone), up to four times per day (max. $16 \mathrm{mg} /$ day) with at least 2 hours between each dose. Both 2 and $4 \mathrm{mg}$ dose strengths of naloxone nasal spray are commercially available, and these doses were thus selected for this study. However, using a single concentration of naloxone and instructing the subjects to dose into one (group A) or both (group B) nostrils was deemed a simpler approach from an operational standpoint. Naloxone is safe and well-tolerated intranasally and the maximum administered daily dose (16mg intranasal (IN)) falls well below the total exposure achieved by intravenous doses that can be used to rescue overdose victims. ${ }^{32}$ Use of study medication, AEs, gambling frequency and gambling expenditure were recorded on a daily basis into a mobile diary.

Study participation required three visits to the clinic and two telephone contacts (see study flow, figure 1). The brief supportive phone calls followed the framework of the BRENDA (a psychosocial program integrating psychosocial treatment and pharmacotherapy) $\operatorname{model}^{33}$ (all visits described online supplement S2).
Visits

Screening visit

At a screening visit (week 0 ) conducted by a research coordinator, the following information was collected after signing the informed consent: preliminary check of inclusion and exclusion criteria; problem-level gambling assessed by SOGS (over the last 12 months) ${ }^{28-30}$; alcohol consumption assessed with the Alcohol Use Disorders Identification Test (AUDIT-C) $^{34-36}$; smoking habits (yes/no); depressive symptoms assessed with the BDI, ${ }^{30}$ background information (age, gender, other medical conditions and medication) and sociodemographic information (education, marital status, employment status, housing conditions). Blood and urine samples were collected for basic haematology and biochemistry tests and to exclude HIV and HCV infection, opioid use and pregnancy. All laboratory tests were conducted in a certified laboratory in Helsinki.

\section{Baseline visit (week 0)}

At a baseline visit (week 0), eligible subjects were assigned to 8-week treatment with as-needed self-administration of nasal naloxone spray as described above.

First, the study physician confirmed the inclusion/ exclusion criteria, assessed medical conditions and issues including other medications being taken, and performed a visual examination of the nasal mucosa using a nasal irritation score on a scale of $0-5$. The definitions of each point of the scale are provided below: $0=$ normal appearing mucosa, no bleeding; 1=inflamed mucosa, no bleeding; 2=minor bleeding which stops within $1 \mathrm{~min}$; $3=$ minor bleeding, taking $1-5 \mathrm{~min}$ to stop; $4=$ substantial bleeding for 4-60 $\mathrm{min}$, does not require medical intervention; $5=$ ulcerated lesions, bleeding which requires medical intervention. The study physician also checked the laboratory results that were sent from the laboratory, 
and screened and evaluated the subject's risk of suicide using a three-item questionnaire. ${ }^{36}$ None of these data were analysed. Subjects meeting the inclusion and exclusion criteria were randomised on a 1:1 basis into the two treatment groups. Subjects were provided with a supply of study medication for the study duration and appropriate information about the study medicine. In addition, all subjects were given a copy of the self-help manual 'Becoming a Winner'. 3738

Subjects were presented a questionnaire assessing their perceptions of the appropriateness for addressing the problem, convenience, effectiveness, risks and adherence (acceptability) and applicability, practicality of applying the treatment, and clarity of the treatment protocol (feasibility) of intranasal medication (see online supplement S3 for translated questionnaire). This questionnaire consisted of 14 questions with 9-point Likert rating scales ( $1=$ not at all to $9=$ extremely). Items were created based on categories for testing acceptability (seven items) and feasibility (seven items). ${ }^{25} \mathrm{~A}$ three-item questionnaire was used to assess motivation for change (importance, readiness and certainty) using an 11-point Likert scale $(0=$ not at all to $10=$ extremely) (see feasibility questionnaire in online supplement S3).

Subjects were trained by the study nurse on the use of a daily mobile questionnaire, and self-administration of the study medication was instructed by the study physician. Text message questions were (1) How many times did you take medication yesterday, with the answering options of zero to four times per day; (2) Did you experience any AEs during the day? The subjects were instructed to record any unusual event in the diary, such as headache, back pain, influenza, nausea, gastrointestinal pain, sports injury and so on. All AEs were rated by the study physician as follows: (1) severity; three-point Likert-scale (1=mild, $2=$ moderate, $3=$ severe); (2) relationship to study medication was rated five-point Likert-scale (1=definitely related to $5=$ notrelated). Adverse drug reactions and unexpected adverse drug reactions and serious adverse events (SAEs) were to be recorded and reported, but none were observed. Other text message questions were (3) Did you gamble yesterday (yes/no); (4) How much money did you spend on gambling (euros); (5) How much time did you spend on gambling (hours and minutes). Subjects were instructed to reply to the text message reminders daily. The next contact (week 2 phone call) was scheduled.

\section{Week 2 and week 5 contacts}

In weeks 2 and 5 , a feasibility assessment of the naloxone nasal spray and an evaluation of the treatment protocol was performed with phone calls by the research coordinator. Questions during the calls were focused on the usability of the study medication (including possible technical issues with the nasal spray device), use of other medications, AEs, usability of the mobile diary (including technical problems sending or receiving text messages) and a brief supportive conversation about problem gambling using the contents of the self-help manual as a guideline. At the end of the week 5 contact, a clinic visit to meet the study physician was scheduled for 3 weeks later (study week 8).

\section{Week 8 visit}

At this end-of-study visit, a 14-item questionnaire was presented in order to evaluate the acceptability and feasibility of the as needed medication and nine questions were asked about the participant's experiences during the treatment. The SOGS (related to gambling behaviours during the trial (see online supplement S4), modified SOGS last 2 months), AUDIT-C and BDI questionnaires were administered. In addition, an examination of the nasal mucosa was conducted. Further treatment referrals were made for those who requested it. One open-ended question was also presented: 'In your opinion, what

Table 1 Pretreatment demographics of all participants and the two treatment groups (median, first and third quartiles for gender, age, problem gambling severity (SOGS), depressive symptoms (BDI) and alcohol consumption (AUDIT-C)

\begin{tabular}{|c|c|c|c|}
\hline & $\begin{array}{l}\text { All participants } \\
(n=18)\end{array}$ & $\begin{array}{l}\text { Group A } \\
(\mathrm{n}=8)\end{array}$ & $\begin{array}{l}\text { Group B } \\
(n=10)\end{array}$ \\
\hline Male \% & 44 & 38 & 50 \\
\hline $\begin{array}{l}\text { Age (years), median; } \\
\text { (first and third quartile) }\end{array}$ & $47.00 ;(40.25,55.50)$ & $47.00 ;(37.25,51.00)$ & $48.00 ;(41.00,56.75)$ \\
\hline $\begin{array}{l}\text { SOGS, median; } \\
\text { (first and third quartiles) }\end{array}$ & 12.00; $(10.00,13.75)$ & 12.00; $(10.75,14.25)$ & 11.50; $(10.0,13.0)$ \\
\hline $\begin{array}{l}\text { BDI, median; } \\
\text { (first and third quartiles) }\end{array}$ & $9.00 ;(4.5,13.75)$ & $14.50 ;(12.75,16.00)$ & $5.00 ;(3.00,7.00)$ \\
\hline $\begin{array}{l}\text { AUDIT-C, median; } \\
\text { (first and third quartiles) }\end{array}$ & $4.00 ;(2.25,5.00)$ & $4.00 ;(2.00,4.25)$ & $4.00 ;(3.00,5.75)$ \\
\hline
\end{tabular}

n, 18; t-test, male/female p value; Wilcoxon's test: age, SOGS (last 12 months) (score: $\geq 5$, probable pathological gambler), BDI (score: 1-9=no depression; 10-18=mild depression; 19-29=moderate depression; 30-63=severe depression) and AUDIT-C (score=4 women indicates hazardous drinking and score $5=$ men indicates hazardous drinking, maximum score 12).

AUDIT, Alcohol Use Disorders Identification Test; BDI, Beck Depression Inventory; SOGS, South Oaks Gambling Screen. 
are the pros/cons of using a nasal spray medication in treating problem gambling?'

\section{Data analyses}

Data were analysed using R Studio and R V.3.4.1. ${ }^{39}$ Descriptive statistics were used to provide summaries about the sample and the measurements. The effect size was estimated using Cliff's delta-within statistic for paired data, which is the difference between the proportion of individual subjects who change in one direction and the proportion of individuals who change in the other direction. The effect size values are negative to show the direction of the desired changes in the SOGS, AUDIT and BDI scores. Regression analysis were used to handle and further estimate the missing values when analysing a gambling diary data, specifically expenditure or time gambled.

\section{RESULTS}

\section{Recruitment}

Of those 30 persons who contacted the research coordinator, 10 persons either refused participation or were excluded from participating in the study. Recruitment was completed when all 20 participants were enrolled. Reasons for refusal are listed in figure 1.

Twenty subjects were enrolled in the study and 18 persons completed the study; both drop outs occurred at week 5 (both for personal reasons and both in group A). Eighteen subjects were thus included in the outcome analysis (8 in group A and 10 in group B).

\section{Descriptors}

Eleven of the 20 subjects were female. The average age was 44 years $(\mathrm{n}=18)($ median $=47$, range $18-74, \mathrm{Q} 1=40.25$, $\mathrm{Q} 3=55.50, \mathrm{IQR}=15.25)$. Eleven of the subjects were married or cohabited, 9 had only a primary school education and 14 were working.

At baseline, the last 12 months SOGS scores of the subjects had a median of 12 (range $8-19, \mathrm{IQR}=3.75$ ). BDI scores had a median of 9 (range $1-19, \mathrm{IQR}=9.25$ ), and alcohol consumption as assessed with AUDIT-C was on
Table 3 Adverse events for both treatment groups coded from the diary and visit reports

\begin{tabular}{lll}
\hline & $\begin{array}{l}\text { Group A } \\
\text { (maximum daily }\end{array}$ & $\begin{array}{l}\text { Group B } \\
\text { (maximum daily } \\
\text { dose } \\
\mathbf{1 6} \mathbf{~ m g} \text { ) }\end{array}$ \\
\hline Adverse event class & dose 8 $\mathbf{m g}$ ) & 3 \\
\hline $\begin{array}{l}\text { Not related } \\
\begin{array}{l}\text { Study medication } \\
\text { related }\end{array}\end{array}$ & 15 & 6 \\
All AEs & 4 & 9
\end{tabular}

n, 18; study medication-related adverse events coded by study physician either related or not related to the study medication. AEs, adverse events.

a moderate level $($ median $=4$, range $0-9, \mathrm{IQR}=2.75) \quad($ see table 1). Two-thirds of the subjects were smokers.

Table 1 here on a scale from 0 to 10 , the subjects perceived their attitudes towards changing their gambling behaviour as follows: importance (median $=10$, range 6-10, $\mathrm{Q} 1=9.75, \mathrm{Q} 3=10.00, \mathrm{IQR}=0.25)$, certainty (median $=5$, range $0-10, \mathrm{Q} 1=4.00, \mathrm{Q} 3=8.00, \mathrm{IQR}=4$ ) and readiness (median $=9$, range $2-10, \mathrm{Q} 1=5.00, \mathrm{Q} 3=10.00$, $\mathrm{IQR}=5.00)$.

Acceptability and feasibility of using the naloxone nasal spray At baseline, the subjects had high perceptions of the acceptability of using nasal spray to treat GD (median $=9$, range 3-9, $Q 1=9, \quad Q 3=9)$, and acceptability remained high also post-treatment (median $=9$, range $1-9, Q 1=9$, Q3=9). The subjects' high perception of the feasibility of the approach did not change from preintervention (median=9, Q1=9, Q3=9) to postintervention (median=9, $\mathrm{Q} 1=9, \mathrm{Q} 3=9$ ).

\section{Experiences from the treatment}

Open-ended questions regarding their experience and opinions of the study. Sixteen of the 18 subjects reported that they would be willing to participate in a similar study in the future. The quotes of the subjects' are in online supplement S5.

Table 2 Group A and group B with $4 \mathrm{mg}$ dose of medicine: number of gambling occasions when probability, minutes and euros spent in gambling after taking medicine

\begin{tabular}{llllll}
\hline & $\begin{array}{l}\text { No of gambling } \\
\text { occasions when } \\
\text { subjects took } \\
\text { medicine and were } \\
\text { gambling }\end{array}$ & $\begin{array}{l}\text { No of gambling } \\
\text { occasions when } \\
\text { subjects took } \\
\text { medicine and were } \\
\text { NoT gambling } \\
\text { dose }\end{array}$ & $\begin{array}{l}\text { Probability of } \\
\text { gambling after } \\
\text { taking medicine }\end{array}$ & $\begin{array}{l}\text { Minutes (mean) } \\
\text { gambled if gambled spent on gambling } \\
\text { after taking } \\
\text { medicine }\end{array}$ & $\begin{array}{l}\text { Eur gambled after } \\
\text { taking medicine }\end{array}$ \\
\hline $\begin{array}{l}\text { Group A } \\
(2 \times 2 \mathrm{mg})\end{array}$ & 15 & 18 & 0.45 & 150 & $129 €$ \\
$\begin{array}{l}\text { Group B } \\
(1 \times 4 \mathrm{mg})\end{array}$ & 14 & 92 & 0.13 & $55 €$ \\
\hline
\end{tabular}

Dose, no of gambling occasions when medicine was taken and subject gambled, no of gambling occasions when medicine was taken and subject did not gamble, of gambling after taking medicine, minutes (mean) gambled if gambled after taking medicine, euros spent in gambling (mean) if gambled after taking medicine, that were recorded in the daily diary were analysed. $\mathrm{n}, 18$. 


\section{SOGS points in both groups, $\mathrm{N}=18$}

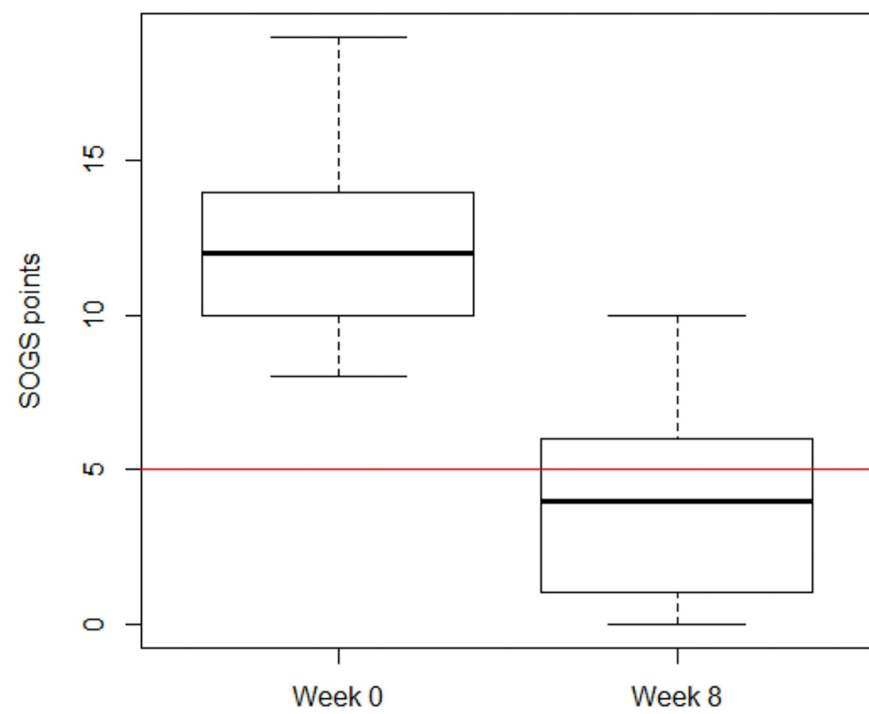

Figure 2 Problem gambling severity measured by South Oaks Gambling Screen (SOGS) before and after the trial (both groups). $\mathrm{N}=18$; SOGS scores were used with the following timeframes; pretreatment (last 12 months) and post-treatment (last 2 months). SOGS score $\geq 5$ refers to a probable pathological gambler. The bottom and top lines are minimum and maximum values. The box includes all values between Q1 and Q3. Bolded line inside the box is the median (Q2) value.

\section{Evaluation of the feasibility of research methods}

Of the 20 enrolled subjects, $18(90 \%)$ completed the 8 -week treatment. Drop out cases were treated as missing data when describing the SOGS, BDI and AUDIT-C scores at study start and end. Any AEs of the discontinued subjects were incorporated into the $\mathrm{AE}$ database.

On $73 \%$ of those days when the study medication was used, no gambling was recorded. The dose that was most used was $4 \mathrm{mg}$ /day regardless of study group. Further, when the daily dose of $4 \mathrm{mg}$ was specifically explored (in group A: $2 \times 2 \mathrm{mg}$; in group B: $1 \times 4 \mathrm{mg}$ ), reductions in gambling were observed (took medicine and gambled vs did not gamble) in group B $(1 \times 4 \mathrm{mg}$ dose $)$ compared with group A $(2 \times 2 \mathrm{mg})$. Probability of gambling when taking medicine in group A $(2 \times 2 \mathrm{mg}$ dose $)$ was 0.45 and the probability of gambling when taking medicine in group B $(1 \times 4 \mathrm{mg})$ was 0.13 (table 2$)$. When one participant who discontinued filling the diary and one drop out were removed from the analyses, there were 8 days which are non-completed, in other words on only $0.8 \%$ of all study days there were no diary entries $(n=18)$. There were instances where the participant did not remember the duration of the gambling time or money spent, this was resolved using regression analysis.

\section{Adverse events}

Subjects in group A reported more AEs (19 events) than those in group B (9 events). The group difference in AEs not related to study medication (group $\mathrm{A}, \mathrm{n}=15$; group B, n=3) was deemed large for a study of this size, but the AEs related to study medication were similar (group $\mathrm{A}, \mathrm{n}=4$, group $\mathrm{B}, \mathrm{n}=6$ ) (table 3 ). The medication 'related' AEs in group A were headache, nausea, itchy nose, stuffy nose and runny nose, while subjects in group B reported fatigue, dizziness and loss of appetite.

\section{Changes in gambling behaviour, depressive symptoms and alcohol use}

At the conclusion of the 8-week trial, a reduction in gambling severity was observed (figure 2). SOGS scores were markedly reduced from baseline values $(n=18)$ (median=12, range 8-19, Q1=10.00, Q3=13.75, $\mathrm{IQR}=3.75$ ) in the repeat scoring carried out at the end of the treatment period (median $=4$, range $0-10, \mathrm{Q} 1=1.25, \mathrm{Q} 3=6.00$, $(\mathrm{IQR}=4.75$; effect size $=-0.8888,95 \% \mathrm{CI} \quad(-0.4251$ to $-0.9830)$ ), indicating a decline in gambling behaviour (table 4). Descriptives of gambling behaviour time (minutes) and money spent in gambling, doses of medication, times gambled per week, mean scores and first and third quartile of euros and time from the gambling diary are reported in table 5 showing fluctuation in all variables.

Table 4 Median, mean, range, IQR, first and third quartiles and effect size and Cls of gambling severity, depressive symptoms and alcohol risk consumption at baseline and after the trial

\begin{tabular}{lllllll}
\hline & & Median & Mean & Range & $\begin{array}{l}\text { IQR; (first and third } \\
\text { quartiles) }\end{array}$ & Effect size (95\% Cl) \\
\hline \multirow{2}{*}{ SOGS } & Baseline & 12.00 & 12.11 & $8-19$ & $3.75 ;(10.00 ; 13.75)$ & $-0.8888(-0.425$ to -0.9830$)$ \\
& Post-treatment & 4.00 & 3.94 & $0-10$ & $4.75 ;(1.25 ; 6.00)$ & $-0.7778(-0.3757$ to -0.9334$)$ \\
\multirow{2}{*}{ BDI } & Baseline & 9.00 & 9.39 & $1-19$ & $9.25 ;(4.5 ; 13.75)$ & $0(0.3229$ to -0.3229$)$ \\
& Post-treatment & 5.50 & 5.67 & $0-12$ & $5.50 ;(2.25 ; 7,75)$ & \\
\multirow{2}{*}{ AUDIT C } & Baseline & 4.00 & 3.89 & $0-9$ & $2.75 ;(2.25 ; 5.00)$ & \\
& Post-treatment & 4.00 & 3.83 & $0-9$ & $3.00 ;(2.00 ; 5.00)$ & \\
\hline
\end{tabular}

$\mathrm{n}, 18$; SOGS (last 12 months vs last 2 months) (score: $\geq 5$, probable pathological gambler), BDI (score: 1-9=no depression; 1018=mild depression; 19-29=moderate depression; 30-63=severe depression) and AUDIT-C (score=4 women indicates hazardous drinking and score $5=$ men indicates hazardous drinking, maximum score 12).

AUDIT, Alcohol Use Disorders Identification Test; BDI, Beck Depression Inventory; SOGS, South Oaks Gambling Screen. 
Table 5 Descriptives of weekly euros and time (in minutes) spent in gambling and milligrams of study medicine taken, occasions gambled in a week presented in group sum; mean scores ( $€$ and time spent in minutes per week) and first and third quartiles of for group A and group B

\begin{tabular}{|c|c|c|c|c|c|c|c|c|}
\hline Week & $€ /$ week & $\begin{array}{l}\text { Time min/ } \\
\text { week on } \\
\text { gambling }\end{array}$ & $\begin{array}{l}\text { mg } \\
\text { /week }\end{array}$ & $\begin{array}{l}\text { Occasions } \\
\text { gambled } \\
\text { /week }\end{array}$ & Mean $€$ & Q1; Q3 & $\begin{array}{l}\text { Mean time/ } \\
\text { week }\end{array}$ & Q1; Q3 \\
\hline \multicolumn{9}{|c|}{ Group A } \\
\hline 1 & 1204 & 1770 & 98 & 14 & 86 & $8.0 ; 100.0$ & 126 & $30.0 ; 240.0$ \\
\hline 2 & 1080 & 1350 & 76 & 10 & 108 & $40.0 ; 200.0$ & 135 & $120.0 ; 180.0$ \\
\hline 3 & 340 & 330 & 52 & 4 & 85 & $27.5 ; 125$ & 82.5 & $17.5 ; 135.0$ \\
\hline 4 & 945 & 1000 & 62 & 8 & 118 & $25.0 ; 210.0$ & 122 & $52.5 ; 135.0$ \\
\hline 5 & 351 & 860 & 52 & 6 & 58 & $25.0 ; 70.0$ & 143 & $120 ; 180.0$ \\
\hline 6 & 217 & 420 & 26 & 5 & 43 & $5.0 ; 100.0$ & 84 & $20.0 ; 180.0$ \\
\hline 7 & 750 & 660 & 16 & 4 & 188 & $137.5 ; 225.0$ & 165 & $52.5 ; 180.0$ \\
\hline 8 & 1445 & 1210 & 34 & 7 & 206 & $55.0 ; 325.0$ & 173 & $75.0 ; 225.0$ \\
\hline \multicolumn{9}{|c|}{ Group B } \\
\hline 1 & 1212 & 2010 & 244 & 12 & 101 & $18.8 ; 82.5$ & 168 & $10.0 ; 80.0$ \\
\hline 2 & 368 & 975 & 272 & 11 & 33 & $11.0 ; 40.0$ & 89 & $15.0 ; 60.0$ \\
\hline 3 & 983 & 955 & 164 & 7 & 140 & $26.0 ; 57.5$ & 136 & $70.0 ; 210.0$ \\
\hline 4 & 584 & 496 & 164 & 8 & 73 & $40.0 ; 97.5$ & 62 & $30.0 ; 67.5$ \\
\hline 5 & 510 & 1155 & 188 & 7 & 73 & $50.0 ; 110.0$ & 165 & $32.5 ; 240.0$ \\
\hline 6 & 618 & 792 & 108 & 9 & 69 & $38.0 ; 68.0$ & 88 & $24.0 ; 60.0$ \\
\hline 7 & 294 & 374 & 108 & 6 & 49 & $21.5 ; 66.0$ & 62 & $25.5 ; 60.0$ \\
\hline 8 & 902 & 693 & 56 & 12 & 75 & $16.5 ; 100.0$ & 58 & $17.5 ; 90.0$ \\
\hline
\end{tabular}

$\mathrm{N}=18$. Missing values: if gambled but both euros and time missing, estimated with mean values of the person. If euros OR time missing, the missing value was estimate with regression analysis.

BDI scores were also lower at study end $(\mathrm{n}=18)$ (median=5.50, range $0-12, \mathrm{Q} 1=2.25, \mathrm{Q} 3=7.75, \mathrm{IQR}=5.50$ ) compared with baseline (median $=9$, range $1-19, \mathrm{Q} 1=4.50$, $\mathrm{Q} 3=13.75, \mathrm{IQR}=9.25$; effect size $=-0.7778,95 \% \mathrm{CI}(-0.3757$ to -0.9334$)$ ). BDI scores improved for 15 subjects, remained the same for two subjects, and increased for one subject. Self-reported alcohol consumption was not changed during the trial (table 4).

\section{DISCUSSION}

To our knowledge, this is the first report of the use of a nasal naloxone spray, administered on an as needed basis, to treat GD. The primary objective of this open-label study was to assess the safety, acceptability and feasibility of use, and outcomes of naloxone nasal spray in the treatment of treatment of GD by combining naloxone nasal spray with brief supportive phone calls.

\section{Acceptability and feasibility of the intervention}

Overall, the subjects' attitudes towards using as-needed naloxone nasal spray were positive, which indicates good acceptance and feasibility of the treatment. A low drop out rate $(10 \%)$ also suggests good adherence to the treatment, much higher than in most previous treatment studies. ${ }^{14}{ }^{15}$ At study start, the subjects' overall rating of importance for changing their gambling behaviour was high. High acceptance and feasibility ratings combined with high readiness for change may have contributed to the good outcome of this trial. ${ }^{40}$ Answers to the openended question also indicated that the subjects perceived the nasal spray medication easy to use and acceptable. However, this sample may not be an accurate reflection of populations currently seeking treatment for gambling issues/problems, since nearly half of the study participants were recruited via newspaper advertisements.

\section{Feasibility of the research methods}

The recruitment process was managed within a similar time frame as in previous studies,${ }^{1541}$ using online sources and local newspaper advertisements. The sample demographics are in line with other corresponding studies. ${ }^{14} 15$

The SOGS (last 12 months) was used as a prescreening instrument, and all potential subjects prescreened with SOGS subsequently fulfilled the diagnostic criteria in the study physician's clinical interview. This implies that the online SOGS prescreen can also be used in a larger, placebo-controlled proof-of-principle study.

Based on diary data, adherence to study medication was acceptable and the study protocol was implemented as planned. Phone calls were conducted by a trained 
research coordinator, who followed the script consistently with each subject-keeping a log that was checked after the study, indicating very good intervention fidelity. Both treatment duration and frequency of appointments were perceived positively by the study subjects. This study used telephone messages to remind the subjects to fill in the daily gambling diary. The naloxone nasal spray device functioned well; one subject reported that the spray bottle had broken, and two subjects reported that the spray did not come out evenly, but they were provided with backup devices that worked well.

The reported AEs were classified by the study physician. There were more reported AEs in the lower dose group (group A). Study medication-related AEs were nausea, headache or loss of appetite, and GI pain, commonly reported with opioid antagonist medications. ${ }^{19}$ As presented in table 3, the frequency of related AEs was not dose dependent. Addition of a placebo arm will be necessary to better understand the relationships between naloxone dose, dosing frequency and AEs. However, no SAEs were detected/reported.

An analysis between of study medicine dose (ie, group A vs group B) and gambling expenditure and time did not indicate dose dependence. There was considerable variation in the frequency of dosing among the participants. Of the 18 subjects completing the trial, only 4 individuals took the maximum permissible dose $(4 \times)$ day) with varying frequency, ranging from 1 to 14 days out of a total of 60 possible days (8 weeks' trial duration). The maximum dosage $(4 \mathrm{x} /$ day) was taken 18 times: 1 subject did this 14 times and the remaining three subjects took the maximum dosage on 1 or 2 days. Participants used study medication on $34 \%$ of all days during their participation. However, in view of the small sample size, rendering the outcome sensitive to confounding factors such as the severity of addiction, larger-scale studies including a placebo control arm will be required to determine a minimum effective dose.

The use of study medication was associated with a reduction in gambling in $73 \%$ of the subjects, as assessed using diary data. Reduction in gambling severity measured with a modified version of SOGS was also observed, but with no apparent differences related to total dose (see figure 2). While the SOGS measure showed a decline in gambling behaviour from pretreatment to post-treatment, it has only been validated as a tool for assessing severity of gambling, with questions framed with the wording: 'Have you ever.... ${ }^{42}$ Thus, in the context of the present study, these observed reductions can only be seen as suggestive, since this particular measure has two limitations: the timeframes pretreatment and post-treatment are very different and thus not comparable, and the SOGS does not measure reduction in urges, yet in this sample the scores reflect reductions in gambling behaviour. Other limitations of our study include lack of a placebo control, a small study size and the use of self-report. The small sample size also prevented us from detecting statistically significant differences between the groups, allowing us only to describe variables, which is in line with this the limitations inherent in a feasibility study. Despite these limitations, depressive symptoms measured by BDI scores decreased for most of the subjects, but these preliminary findings must also be interpreted with caution.

Descriptive results from the gambling diary show that gambling behaviour is fluctuating in nature, even though use of study medication tended to decline in both groups during the 8-week treatment period and group A reported an increase in gambling expenditure from pretreatment to post-treatment. Achieving sustained changes in behaviour and adherence to study medication may require more psychosocial support and follow-up, and a longer duration of intervention. Changes in gambling behaviour may be sustained with more structured, but nonetheless minimal psychosocial support, for example, increasing participants' awareness of gambling and triggers for gambling, for example, by adding The Gambling Abstinence Self-efficacy Scale ${ }^{43}$ as a therapeutic tool along with a self-help booklet. ${ }^{3738}$ Further, better assessment tools for gambling urge and severity of gambling ${ }^{44-46}$ would give a more accurate picture of gambling behaviour and enable us to better measure treatment efficacy.

\section{What is next?}

A randomised, placebo-controlled clinical trial (ClinicalTrials.gov: NCT03430180: https://clinicaltrials.gov/; and EudraCT 2017-001946-93) in which we have increased psychologist appointments, provided a self-help booklet, regularly review the gambling diary and adherence to study medication, and will give participants feedback every 3 weeks. The naloxone nasal spray will be used in the same as needed manner, and the primary objective is to investigate the efficacy of naloxone in adults with GD. The secondary objectives are to determine the effects of intranasal naloxone on gambling severity, gambling expenditure, gambling frequency and duration of gambling. The safety of intranasal naloxone will also be monitored. The duration of the upcoming trial is 12 weeks, with three clinic visits (baseline and weeks 6 and 12) and two supportive phone calls (weeks 3 and 9). ${ }^{37} 38$ Because there are no medications approved to treat GD, behavioural interventions are viewed as Standard of Care (SOC). In order for naloxone to be viewed as effective in treating $\mathrm{GD}$, it must produce a clinically meaningful effect on gambling behaviours over and above SOC.

\section{CONCLUSIONS}

The acceptability and feasibility of using the naloxone nasal spray were high in this pilot study. AEs were consistent with those reported after oral and parenteral administration of opioid antagonists. This small, openlabel study reflects a general tendency across groups for gambling behaviour to reduce. The study resulted in several concepts that were employed to develop the study protocol for the next phase, a larger, randomised, placebo-controlled trial. These results, together with a growing 
body of evidence for the pivotal role of the brain's opioid systems in addictions, ${ }^{47-49}$ highlight the need to further investigate the utility of intranasal naloxone in the treatment of GD.

\section{Patient and public involvement}

This research was done without patient involvement. Patients were not invited to comment on the study design and were not consulted to develop patient relevant outcomes or interpret the results. Patients were not invited to contribute to the writing or editing of this document for readability or accuracy. Patients were informed about the time of dissemination of the results.

\section{Author affiliations}

${ }^{1}$ Department of Public Health Solutions, Terveyden ja hyvinvoinnin laitos, Helsinki, Finland

${ }^{2}$ Faculty of Social Science, Department of Psychology and Speech Language Pathology, Turun Yliopisto, Turku, Finland

${ }^{3}$ Alcohol, Drugs and Addictions Unit, Terveyden ja hyvinvoinnin laitos, Helsinki, Finland

${ }^{4}$ Clinicum, University of Helsinki, Helsinki, Finland

${ }^{5}$ Faculty of Natural Sciences, University of Tampere, Tampere, Finland

${ }^{6}$ Ita-Suomen yliopisto Terveystieteiden tiedekunta, Kuopio, Finland

${ }^{7}$ Opiant Pharmaceuticals, Santa Monica, USA

${ }^{8}$ Institute of Biomedicine, University of Turku, Turku, Finland

${ }^{9}$ Abdominal Center, University and University of Helsinki, Helsinki, Finland

Acknowledgements The authors thank Dr Phil Skolnick for his assistance in preparing the manuscript for publication and statistician Jukka Kontto for his advice.

Contributors SC, HA, AHS and MS were responsible for the study conception and design. SC, HA, NM and RC conducted literature searches and provided summaries of previous studies. JH performed the data analysis; data analysis and data interpretation were independently performed by SC, HA, JH, AHS, NM and MS. SC, $\mathrm{HA}, \mathrm{JH}, \mathrm{AHS}, \mathrm{NM}, \mathrm{MS}$ and RC made critical revisions to the paper for important intellectual content. RC provided background information and intellectual input that was important for study design, protocol planning and interpretation of the results, but was not directly involved in the formulation of the conclusions presented. The data interpretation and manuscript preparation were independently verified by the non-industry authors (SC, HA, JH, AHS, NM, MS). All authors read and approved the final version.

Funding This work was supported by the Ministry of Social Affairs and Health, Helsinki, Finland, funded the study ( 52 Appropriation of the Lotteries Act). The Ministry had no role in the study design, analysis or interpretation of the results. The study medication was donated by Opiant Pharmaceuticals.

Competing interests SC, NM, JH, AHS and HA declare no conflict of interest in relation to this manuscript. $\mathrm{RC}$ is a full time employee and shareholder of Opiant Pharmaceuticals. MS is part-time employee, board member and shareholder of Clinical Research Services Turku-CRST 0y, a clinical contract research organisation for the pharmaceutical industry. Previous research on nasal naloxone NALPET-study (EudraCT-number) by MS and HA, SC and AHS have received grant support from Opiant Pharmaceuticals.

\section{Patient consent for publication Obtained.}

Ethics approval The study protocol, the informed consent form and other study related materials were reviewed and approved by the Finnish Medicines Agency Fimea (KInro 128/2016) and the National Ethics Committee (/2016).

Provenance and peer review Not commissioned; externally peer reviewed.

Data sharing statement Data can be accessed upon request from the investigators.

Open access This is an open access article distributed in accordance with the Creative Commons Attribution Non Commercial (CC BY-NC 4.0) license, which permits others to distribute, remix, adapt, build upon this work non-commercially, and license their derivative works on different terms, provided the original work is properly cited, appropriate credit is given, any changes made indicated, and the use is non-commercial. See: http://creativecommons.org/licenses/by-nc/4.0/.

\section{REFERENCES}

1. American Psychiatric Association. Diagnostic and Statistical Manual of Mental Disorders. 5th edn. Arlington, VA: American Psychiatric Association, 2013.

2. Grant JE, Potenza MN, Weinstein A, et al. Introduction to behavioral addictions. Am J Drug Alcohol Abuse 2010;36:233-41.

3. Langham $\mathrm{E}$, Thorne $\mathrm{H}$, Browne $\mathrm{M}$, et al. Understanding gambling related harm: a proposed definition, conceptual framework, and taxonomy of harms. BMC Public Health 2016;16:1-23.

4. Slutske WS. Natural recovery and treatment-seeking in pathological gambling: results of two U.S. national surveys. Am J Psychiatry 2006;163:297-302.

5. Castrén S, Salonen AH, Lahti T, et al. Rahapeliongelmaisten hoito on vielä hajanaista. (Services for problem gamblers in Finland). Suomen lääkärilehti 2015;70:650-5.

6. Melville KM, Casey LM, Kavanagh DJ. Psychological treatment dropout among pathological gamblers. Clin Psychol Rev 2007;27:944-58.

7. Hodgins DC, Stea JN, Grant JE. Gambling disorders. The Lancet 2011;378:1874-84

8. Yau YH, Potenza MN. Gambling disorder and other behavioral addictions: recognition and treatment. Harv Rev Psychiatry 2015;23:134-43.

9. Łabuzek K, Beil S, Beil-Gawełczyk J, et al. The latest achievements in the pharmacotherapy of gambling disorder. Pharmacol Rep 2014;66:811-20.

10. Pallesen S, Mitsem M, Kvale G, et al. Outcome of psychological treatments of pathological gambling: a review and meta-analysis. Addiction 2005;100:1412-22.

11. Hodgins DC, Currie S, el-Guebaly N, et al. Brief motivational treatment for problem gambling: a 24-month follow-up. Psychol Addict Behav 2004;18:293-6.

12. Grant JE, Potenza MN, Hollander E, et al. Multicenter investigation of the opioid antagonist nalmefene in the treatment of pathological gambling. Am J Psychiatry 2006;163:303-12.

13. Grant JE, Kim SW, Hartman BK. A double-blind, placebo-controlled study of the opiate antagonist naltrexone in the treatment of pathological gambling urges. J Clin Psychiatry 2008;69:783-9.

14. Grant JE, Odlaug BL, Potenza MN, et al. Nalmefene in the treatment of pathological gambling: multicentre, double-blind, placebocontrolled study. Br J Psychiatry 2010;197:330-1.

15. Kovanen L, Basnet S, Castrén S, et al. a randomised, double-blind, placebo-controlled trial of as-needed naltrexone in the treatment of pathological gambling. Eur Addict Res 2016;22:70-9.

16. Toneatto T, Brands B, Selby P. A randomized, double-blind, placebo-controlled trial of naltrexone in the treatment of concurrent alcohol use disorder and pathological gambling. Am J Addict 2009;18:219-25.

17. Meyer MC, Straughn AB, Lo MW, et al. Bioequivalence, doseproportionality, and pharmacokinetics of naltrexone after oral administration. J Clin Psychiatry 1984;45:15-19.

18. Ingman K, Hagelberg N, Aalto S, et al. Prolonged central mu-opioid receptor occupancy after single and repeated nalmefene dosing. Neuropsychopharmacology 2005;30:2245-53.

19. Krieter P, Chiang N, Gyaw S, et al. Pharmacokinetic properties and human use characteristics of an fda-approved intranasal naloxone product for the treatment of opioid overdose. J Clin Pharmacol 2016;56:1243-53.

20. Tylleskar I, Skulberg AK, Nilsen T, et al. Pharmacokinetics of a new, nasal formulation of naloxone. Eur J Clin Pharmacol 2017;73:555-62.

21. Johansson J, Hirvonen J, Lovró Z, et al. Intranasal naloxone rapidly occupies brain mu-opioid receptors in human subjects. Neuropsychopharmacology 2019:1-7.

22. Bowen DJ, Kreuter M, Spring B, et al. How we design feasibility studies. Am J Prev Med 2009;36:452-7.

23. Rajadhyaksha V. Conducting feasibilities in clinical trials: an investment to ensure a good study. Perspect Clin Res 2010;1:106-9.

24. Tickle-Degnen $\mathrm{L}$. Nuts and bolts of conducting feasibility studies. Am $J$ Occup Ther 2013;67:171-6.

25. Sidani S, Braden CJ. Evaluating nursing interventions: a theorydriven approach. Thousand Oaks: SAGE Publications, 1998.

26. Bell J, Byron G, Gibson A, et al. A pilot study of buprenorphinenaloxone combination tablet (Suboxone) in treatment of opioid dependence. Drug Alcohol Rev 2004;23:311-7. 
27. Yoon G, Kim SW, Thuras P, et al. Safety, tolerability, and feasibility of high-dose naltrexone in alcohol dependence: an open-label study. Hum Psychopharmacol 2011;26:125-32.

28. Lesieur HR, Blume SB. The South Oaks Gambling Screen (SOGS): a new instrument for the identification of pathological gamblers. Am J Psychiatry 1987;144:1184-8.

29. Lesieur HR, Blume SB. Revising the South Oaks Gambling Screen in different settings. J Gamb/ Stud 1993;9:213-23.

30. Rosenthal RJ. et a/Pathological gambling and problem gambling: Problems of definition and diagnosis. In: Shaffer HJ, Stein SA, Gambino B, Cummings TN, . eds. Compulsive gambling: theory, research and practice. Lexington, MA: Lexington Books, 1989:101-25.

31. Beck AT, Steer RA, Brown GK. Manual for the Beck Depression Inventory-II. San Antonio, TX: Psychological Corporation, 1996.

32. Boyer EW. Management of opioid analgesic overdose. N Engl J Med 2012;367:146-55.

33. Starosta AN, Leeman RF, Volpicelli JR. The BRENDA model: integrating psychosocial treatment and pharmacotherapy for the treatment of alcohol use disorders. J Psychiatr Pract 2006;12:80-9.

34. Babor TF, de la Fuente JR, Saunders J, et al. AUDIT The Alcohol Identification Test. World Health Organization 1992.

35. Aalto M, Alho H, Halme JT, et al. AUDIT and its abbreviated versions in detecting heavy and binge drinking in a general population survey. Drug Alcohol Depend 2009;103:25-9.

36. Ladouceur R, Lachance S, Gambling OP, et al. Treatments that work. New York: Oxford University Press, 2007.

37. Hodgins DC, Makarchuk K. Becoming a winner: defeating problem gambling. Edmonton, Alberta, Canada: Alberta Alcohol and Drug Abuse Commission, 2002.

38. Semantex CS. In: Hodgins DC, Makarchuk K, eds. Avaimia rahapeliongelman hallintaan (Translated) Becoming a winner: Defeating problem gambling. Helsinki: National Institute for Health and Welfare, 2018.
39. R Core Team: R: A language and environment for statistical computing, R Foundation for statistical Computing, Vienna, Austria. 2013 http://www.R-project.org/ (Accessed 30 Feb 2017).

40. Kushnir V, Godinho A, Hodgins DC, et al. Motivation to quit or reduce gambling: associations between self-determination theory and the transtheoretical model of change. J Addict Dis 2016;35:58-65.

41. Lahti T, Halme J, Pankakoski M, et al. Characteristics of treatment seeking finnish pathological gamblers: baseline data from a treatment study. Int J Ment Health Addict 2013;11:307-14.

42. Pickering D, Keen B, Entwistle G, et al. Measuring treatment outcomes in gambling disorders: a systematic review. Addiction 2018;113:411-26.

43. Hodgins D, Peden N, Makarchuk K. Self-efficacy in pathological gambling treatment outcome: development of a gambling abstinence self-efficacy scale (GASS). Int Gamb/ Stud 2004;4:99-108.

44. Kim SW, Grant JE, Potenza MN, et al. The Gambling Symptom Assessment Scale (G-SAS): a reliability and validity study. Psychiatry Res 2009;166:76-84.

45. Gerstein DR, Murphy SA, Toce MT, et al. Gambling impact and behavior study: report to the National Gambling Impact Study Commission. Chicago: National Opinion Research Center at the University of Chicago, 1999.

46. Ferris J, Wynne H. The Canadian problem gambling index: final report. Ottawa: Canadian Centre on Substance Abuse, 2001.

47. Heinz A, Reimold M, Wrase J, et al. Correlation of stable elevations in striatal mu-opioid receptor availability in detoxified alcoholic patients with alcohol craving: a positron emission tomography study using carbon 11-labeled carfentanil. Arch Gen Psychiatry 2005;62:57-64.

48. Williams TM, Daglish MR, Lingford-Hughes A, et al. Brain opioid receptor binding in early abstinence from opioid dependence: positron emission tomography study. Br J Psychiatry 2007;191:63-9.

49. Williams TM, Davies SJ, Taylor LG, et al. Brain opioid receptor binding in early abstinence from alcohol dependence and relationship to craving: an [11C]diprenorphine PET study. Eur Neuropsychopharmacol 2009;19:740-8. 
Correction: treating gambling disorder with as needed

administration of intranasal naloxone: a pilot study to evaluate acceptability, feasibility and outcomes

Castrén S, Mäkelä N, Haikola J, et al. Treating gambling disorder with as needed administration of intranasal naloxone: a pilot study to evaluate acceptability, feasibility and outcomes. BMJ Open 2019;9:e023728. doi: 10.1136/bmjopen-2018-023728

This article was previously published with error in 'Competing interests' statement.

The correct 'Competing interests' statement is mentioned below:

SC, NM, JH, AHS and HA declare no conflict of interest in relation to this manuscript. RC is a full time employee and shareholder of Opiant Pharmaceuticals. MS is part-time employee, board member and shareholder of Clinical Research Services Turku-CRST Oy, a clinical contract research organisation for the pharmaceutical industry. Previous research on nasal naloxone NALPET-study (EudraCT-number 2015002681-23) by MS and HA have received grant support from Opiant Pharmaceuticals.

Open access This is an open access article distributed in accordance with the Creative Commons Attribution Non Commercial (CC BY-NC 4.0) license, which permits others to distribute, remix, adapt, build upon this work non-commercially, and license their derivative works on different terms, provided the original work is properly cited, appropriate credit is given, any changes made indicated, and the use is non-commercial. See:http://creativecommons.org/licenses/by-nc/4.0/.

(C) Author(s) (or their employer(s)) 2019. Re-use permitted under CC BY-NC. No commercial re-use. See rights and permissions. Published by BMJ.

BMJ Open 2019;9:e023728corr1. doi:10.1136/bmjopen-2018-023728corr1

A) Check for updates 